\title{
Combination of Spironolactone and Sitagliptin Improves Clinical Outcomes of Outpatients with COVID-19: An Observational Study
}

Mohammad Ali Davarpanah ${ }^{1}$, Reuben Adatorwovor ${ }^{2}$, Yasaman Mansoori ${ }^{3}$, Fatemeh Sadat Rajaie Ramsheh ${ }^{4}$, Amir Parsa ${ }^{5}$, Mehdi Hajiani $^{6}$, Hossein Faramarzi ${ }^{7}$, Ramakanth Kavuluru ${ }^{8}$, Kamyar Asadipooya ${ }^{9}$

${ }^{1}$ Mohammad Ali Davarpanah, MD; Professor of Medicine, Shiraz HIV/AIDS Research Center, Shiraz University of Medical Sciences, Shiraz, Iran. Email: Davarpanah@sums.ac.ir

${ }^{2}$ Reuben Adatorwovor, PhD; Department of Biostatistics, University of Kentucky, Lexington, KY, USA. Email: radatorwovor@uky.edu

${ }^{3}$ Yasaman Mansoori, MD; Student Research Committee, Shiraz University of Medical Sciences, Shiraz, Iran. Email: Yaas.mansouri@gmail.com

${ }^{4}$ Fatemeh Sadat Rajaie Ramsheh, MD; Student Research Committee, Shiraz University of Medical Sciences, Shiraz, Iran. Email: Elhamrj96@gmail.com

${ }^{5}$ Amir Parsa, MD; Student Research Committee, Shiraz University of Medical Sciences, Shiraz, Iran. Email: amirparsa1996@yahoo.com

${ }^{6}$ Mehdi Hajiani, MD; Student Research Committee, Shiraz University of Medical Sciences, Shiraz, Iran. Email: Hajiyanimehdi@gmail.com

${ }^{7}$ Hossein Faramarzi, MD; Assistant Professor of Medicine, Department of Community Medicine, Shiraz University of Medical Sciences, Shiraz, Iran. Email: Hossainfaramarzi@yahoo.com

${ }^{8}$ Ramakanth Kavuluru, PhD; Associate Professor, Division of Biomedical Informatics, Department of Internal Medicine, University of Kentucky, Lexington, KY, USA. Email: ramakanth.kavuluru@uky.edu

Corresponding Author: 
${ }^{9}$ Kamyar Asadipooya, MD

Assistant Professor of Medicine, Department of Medicine, Division of Endocrinology, Diabetes, and Metabolism, Barnstable Brown Diabetes and Obesity Center, University of Kentucky, Lexington, KY 40504, USA.

Email: kas224@uky.eduu and kamiasadip@yahoo.comm

Address: Barnstable Brown Diabetes Center, 2195 Harrodsburg Rd, Suite 125, Lexington, KY 40504

Office Phone: 859-323-5821 Fax: 859-257-1078

ORCiD number: 0000-0003-4484-1971 (K. Asadipooya)

\section{Abbreviations}

ACE2, angiotensin-converting enzyme 2; ADAM17, Disintegrin and metalloproteinase domain-containing protein 17; COVID-19, coronavirus disease 2019; CRP, C-reactive protein; DPP4, dipeptidyl peptidase-4; ER, emergency room; SARS-CoV-2, severe acute respiratory syndrome coronavirus 2; SUMS, Shiraz University of Medical Sciences; TMPRSS2, transmembrane protease serine 2, TNF, tumor necrosis factor.

\section{Abstract Word Count: 289}

\section{Manuscript total word count: 2455}

Running title: Combination of spironolactone and sitagliptin in outpatient COVID-19 cases

\section{Abstract}


Background: Coronavirus disease 2019 (COVID-19) leads to hospitalization and death, especially in elderly and those with comorbidities. There are evidences showing that sitagliptin and spironolactone can potentially improve the clinical outcomes of COVID-19 cases. In this observational study on acutely symptomatic outpatient COVID-19 cases, we investigated the effects of spironolactone and sitagliptin on the outcomes of the disease.

Methods: This prospective cohort study was conducted at Shiraz University of Medical Sciences Clinics during the fifth wave of the COVID-19 pandemic between July 2021 and September 2021. We followed mild to moderate symptomatic COVID-19 patients, who were treated with either combination (spironolactone $100 \mathrm{mg}$ daily and sitagliptin $100 \mathrm{mg}$ daily) or standard (steroid, antiviral and/or supportive care) therapy up to 30 days. Our primary outcome was hospitalization rate. The secondary outcomes included ER visit, duration of disease, and complications, such as hypoglycemia, low blood pressure or altered mental status.

Results: Of the 206 patients referred to clinics, 103 received standard therapy and 103 treated with combination therapy. There were no significant differences in baseline characteristics, except for slightly higher clinical score in control group (6.92 \pm 4.01 control, 4.87 \pm 2.92 combination; $P<0.0001)$. Treatment with combination therapy was associated with lower admission rate $(5.8 \%$ combination, $22.3 \%$ control; $P=0.0011)$, ER visits $(7.8 \%$ combination, $23.3 \%$ control; $P=0.0021)$ and average duration of symptoms $(6.67 \pm 2.30$ days combination, $18.71 \pm 6.49$ days control; $P=<0.0001)$.

Conclusion: In this prospective cohort study of acutely ill outpatients with COVID-19, the combination of sitagliptin and spironolactone reduced duration of COVID infection and hospital visits better than standard therapeutic approaches. The effects of combination of sitagliptin and spironolactone in COVID-19 patients should be further verified in a double blind, randomized, placebocontrolled trial.

Iranian Registry of Clinical Trial: IRCT registration number: IRCT20201003048904N2, Registration date: December 10, 2020

Source of funding: Shiraz University of Medical Sciences supported this project. 


\section{Introduction}

More than five million people have died from coronavirus disease 2019 (COVID-19) since the pandemic has started (1). Patients with comorbidities, especially men and elderly, are at higher risk for death or hospitalization (2). Although being vaccinated was associated with reduced hospitalization and mortality (3), there are concerns regarding vaccine efficacy against new variants of coronavirus (4). Therefore, the role of an effective and safe treatment would be crucial.

There are substantial variations between different guidelines, possibly due to lack of enough evidence or limited efficacy of current treatments (5). Monoclonal antibodies, especially the combination form and early treatment, improved the outcomes by reducing duration of illness, hospitalization and death $(6,7)$. However, severe acute respiratory syndrome coronavirus 2 (SARS-CoV-2) has rapidly evolved with the mutations of the spike protein and generation of new variants $(8,9)$, which ended up reducing the beneficial effects of vaccine and monoclonal antibodies $(10,11)$. In addition, some of the therapeutic options, such as monoclonal antibodies and convalescent plasma, are not broadly available and generally require a hospital visit. Hence, blocking virus entry into the cells through its receptor would be a potential alternative to reduce viral replication and severity of the disease.

SARS-CoV-2 enters into the host cell mainly through interacting with the transmembrane protein angiotensin-converting enzyme 2 (ACE2) (12) and, probably, dipeptidyl peptidase 4 (DPP4) $(13,14)$. SARS-CoV-2 has even higher affinity to human ACE2 compared to SARS-CoV (15), which makes it dependent on ACE2 as a major receptor for cell entry (16). Nevertheless, during the acute infection, the enormous virus replication may overwhelm the ACE2 receptors and undertake DPP4 receptors for cellular entry. As a result, blocking virus entry during the acute illness by reducing the interaction of SARS-CoV-2 spike glycoprotein with ACE2 and DPP4 receptors simultaneously can result in better clinical outcomes.

The transmembrane protease serine protease-2 (TMPRSS-2) and ADAM metallopeptidase domain 17 (ADAM17) participate in cleaving ACE2 and priming the S glycoprotein, which potentiate the virus endocytosis. ACE2 has two forms: soluble and membrane bound (16-18). The binding of SARS-CoV-2 to soluble ACE2 increases weight and diameter of viral particles, leading to a higher 
chance of virus attachment to the cell membrane and engulfment (19). Spironolactone, as a mineralocorticoid receptor blocker with anti-androgenic effects, can reduce TMPRSS-2 expression (20,21), inhibit ADAM17 (22), decrease soluble ACE2 plasma level (23), but increases ACE2 expression on cell membrane (24). Moreover, spironolactone reduces inflammation with the advantageous effects on oxidative injury and hypercoagulability (21). Consequently, spironolactone can potentially reduce viral entry and improve clinical conditions of acutely ill COVID-19 cases.

DPP4 inhibitors are associated with lower mortality and intubation risk in COVID-19 patients with diabetes (25-27). Moreover, they could improve clinical outcomes and inflammatory markers (28). This could be potentially due to their immunomodulatory roles (29) and blocking the possible interaction between SARS-CoV-2 spike protein and DPP4 receptors $(13,30)$.

In this study, we propose and assess the hypothesis that spironolactone and sitagliptin (a DPP4 inhibitor), by affecting inflammation and coronavirus cell entry through ACE2 and DPP4, could potentially reduce hospitalization of outpatients with COVID-19, without causing serious adverse events.

\section{Methods}

Study design and population. A prospective cohort study was conducted at Shiraz University of Medical Sciences (SUMS) clinics during the fifth wave of the COVID-19 pandemic in Iran between July 2021 and September 2021, when the delta and subsequent variants of SARS-CoV-2 were dominant (31). The attending physicians provided the care in the institutionalized clinics. We enrolled 206 confirmed or probable adult outpatient cases of SARS-CoV-2 infection according to WHO and CDC definitions (32). The eligible patients were at least 18 years of age and had laboratory confirmed SARS-CoV-2 infection (nasal/throat swabs positive for SARSCoV-2 by RT-PCR) or positive history of exposure to COVID-19 patients besides typical clinical manifestations (33). Exclusion criteria were ongoing mineralocorticoid receptor antagonists (including spironolactone) or DPP4 inhibitors (including sitagliptin) 
treatment. Patients were recruited into two cohort groups (103 patients either in cohort group A or B). Patients in cohort group A received the standard therapy for COVID-19, including supportive care (oral hydration, antipyretics, etc.), antivirals (remdesivir or favipiravir), or steroids based on the severity of their symptoms. Patients in cohort group B received spironolactone 100 mg daily and sitagliptin $100 \mathrm{mg}$ daily. We prescribed a 10-day regimen of combination and told the patients to continue the medications until recovery or call the clinic for further refills. We used combination therapy as an add-on to the antiviral (favipiravir) for 22 patients according to the national COVID-19 committee recommendations (34). We did not use any steroids in the combination group.

We calculated the clinical severity score (Table 1) determined by sex, age, clinical conditions, functional performance, and oxygen requirement using a previously validated scoring tool for outcomes prediction in acutely ill adult patients with COVID-19. The scale ranged from 0 to 29 , with higher scores reflecting worse clinical conditions and scores greater than four showing high sensitivity for recognizing patients with high risk for adverse events (Table 1) (35).

Two follow-ups were conducted one week and one month after the intervention in person or by phone calls. We asked the patients about the need for hospitalization and ER visits. We also recorded duration of disease, adherence to the medication, medication intolerance, and possible complications, such as hypotension, hypoglycemia or drug reaction.

Recovery of COVID-19 was defined as a resolution of fever without using fever-reducing agents and improvement of other symptoms. We compared the clinical outcomes, including hospitalization, emergency room (ER) visits, duration of treatment and complications between the groups.

Clinical data. The research physicians collected and recorded data, including the baseline characteristics, medical history (medications, comorbidities), clinical conditions, hospitalization rate, ER visits, and complications. The comorbidities include diabetes (on medication or hemoglobin A1C > 6.5), hypertension (on medication or blood pressure > 140/90), cardiovascular disease, renal disease, liver disease, lung disease, neurologic disorder, malignancy, hematologic disorders, immune deficiency (transplant etc.), rheumatologic disorder, and hypothyroidism. 
The primary endpoint was the rate of hospitalization between two groups. Secondary endpoints included emergency room (ER) visits, duration of treatment, and intervention related complications.

The ethics committee of Shiraz University of Medical Sciences (IR.SUMS.MED.REC.1399.550) approved the study. We designed the study according to the declaration of Helsinki and Iranian national guidelines for ethics in research. The research physicians deidentified the patients' information after collection and prepared a code for re-identification. The University of Kentucky received the de-identified data for statistical analysis. The Shiraz University of Medical Sciences sponsored the study. The Institutional Review Boards of the University of Kentucky, and Shiraz University of Medical Sciences approved the study.

\section{Statistical Analysis}

Descriptive summaries for the data from the two cohort groups were reported in terms of means and standard deviations, and counts and their corresponding proportions. Specifically, we compared the baseline characteristics across the cohort groups using t- and Mantel-Haenzel chi-square tests for continuous and categorical variables respectively. The main outcome of this analysis is COVID19 hospitalization and we tested hospitalization rate among the cohort groups using the Kaplan-Meier curve and log-rank test.

Additionally, we compare the odds of hospitalization using univariate logistic regression model for each covariate. Multiple logistic regression model was fitted to dichotomized hospitalization outcome while adjusting for all covariates in a multivariate setting. Such covariates include demographic variables such as age, sex, and clinical variables including duration of disease (COVID-19), ER visit, baseline clinical score, prior COVID-19 infection, vaccination status, and comorbidities. We defined comorbidities to be patients who had any of the following: diabetes, hypertension, heart disease, kidney disease, lung disease, liver disease, hypothyroidism, cancer, and hematologic disease. We presented the odds ratio, its $95 \%$ confidence interval with its associated p-value for each of the covariates in the model. The odds ratio compares the risk of hospitalization among the two cohort groups. A positive coefficient lower than 1 indicates lower risk while a positive coefficient larger than 1 indicates a higher risk associated with the covariate in comparing hospitalization rate in the cohort groups. 
All models were fitted using SAS logistics procedures and all analyses were performed using SAS Version 9.4 (TS1M1 SAS Institute Inc., Cary, NC) and R statistical Software. We used the standard 5\% significance level for testing our entire hypothesis with the rejection of the null hypothesis for p-values less than 0.05 .

\section{Results}

Patient Characteristics. A total of 103 patients were treated with combination therapy (spironolactone 100 mg daily and sitagliptin $100 \mathrm{mg}$ daily), while 103 patients received the standard of care. Almost half of them had +PCR results $(57.3 \%$ standard, $49.5 \%$ combination; $P=0.2650$ ), and the rest had history of exposure to COVID-19 with typical clinical manifestations. Baseline demographic characteristics of the two groups are shown in Table 2. The mean age was almost similar (41.50 \pm 12.19 control, $42.45 \pm$ 13.11 combination, $P=0.5941)$ and there were no significant differences in male sex $(41.7 \%$ control, $35.0 \%$ combination, $P=$ 0.3170). Both cohort groups did not have major differences concerning other demographic or clinical characteristics, except for clinical score was higher in control group (6.92 \pm 4.01 control, $4.87 \pm 2.92$ combination; $P<0.0001)$. In addition, there were no differences in comorbidities and medications, except combination group did not receive steroid (Table 2).

Clinical Outcomes. Patients in cohort group A, treated with combination therapy have had better clinical outcomes. They had significantly lower hospitalization rate $(5.8 \%$ combination, $22.3 \%$ control; $P=0.0011)$ and ER visit rate $(7.8 \%$ combination, $23.3 \%$ control; $P=0.0021)$. The duration of disease was significantly less in combination group $(6.67 \pm 2.30$ days combination, $18.71 \pm 6.49$ days control; $P<0.0001)$. Although, the control group had higher clinical score initially, the average scores in both cohort groups were greater than four, indicating higher risk of adverse outcomes comparably (35). The results from the Kaplan-Meier curve (Figure 1) and log-rank test show a significant difference in time to hospitalization, p-value $<0.001$ between patients who received combination therapy compared to the patients who received standard control therapy. Thus, patients on the combination therapy had significantly lower probability of hospitalization compared to patients on the standard control therapy. In a multivariate analysis, 
where we adjusted for appropriate covariates, the odds ratio for hospitalization was significantly lower in the combination therapy group than the control therapy group (OR 0.177, CI 0.065-0.486; $P=0.0008)$, Table 3.

In terms of medication related complications, three patients in combination group reported adverse events between 2 and 6 days after starting medications, two reported drops in blood pressure and blood sugar and one indicated drops in blood pressure. However, they did not need an ER visit or hospitalization and recovered after stopping medications.

\section{Discussion}

The COVID-19 pandemic continues to affect many countries even after vaccination drives and the presence of promising treatments, such as antivirals, convalescent plasma transfusion therapy and monoclonal antibodies (36). Vaccination was broadly advertised with the aim of reducing hospitalization and death, which was shown to be beneficial (3). However, there is a concern regarding their availability in developing countries (37) and efficacy against certain variants of SARS-CoV-2 strains (4). Furthermore, early treatment of outpatient cases with self-isolation at home seems to be helpful for reducing hospitalization and mortality effectively (38).

Therefore, it is important to introduce an effective medication, which can be used safely for outpatients, to improve clinical outcomes and reduce hospitalization of COVID-19.

In the current study, the spironolactone and sitagliptin combination therapy reduced duration of illness, hospitalization rate, and ER visit rate significantly without causing serious adverse events. The proposed mechanisms of those medications include blocking virus entry, reducing viral replication, and alleviating virus mediated inflammation or oxidative injury $(21,39,40)$.

A reasonable mechanism for increased virus infectivity would be the changes in biophysics of virus after attaching to soluble ACE2, which increases the weight and radius of viral particles, and results in escalating virus entry into the human cells (19). It has been shown that administration of the bioengineered soluble ACE2 variant, which was shorter than native soluble ACE2, could effectively 
reduce the infectivity of SARS-CoV-2 (41,42). This could be due to two reasons: (1) soluble ACE2 acting as a decoy receptor to reduce viral uptake or (2) native soluble ACE2 being replaced by the lighter recombinant soluble ACE2, resulting in lighter viral particles with lowered ability for cell entry. TMPRSS2 and ADAM17 (TNF-alpha converting enzyme) cleave ACE2 and potentiate viral uptake (43). The SARS-CoV-2 infection increases expression of ADAM17 and TMPRSS2 (18), down regulates ACE2 receptor. The activation of shedding process of ACE2 can potentially trigger inflammation $(44,45)$. Therefore, SARS-CoV-2 infection initiates a vicious cycle of increasing soluble ACE2 level, more infectivity, reducing ACE2 on cell membrane and further inflammation.

Spironolactone has negative effects on TMPRSS-2 (20,21) and ADAM17 (22), which leads to breaking the vicious cycle and reducing infectivity of SARS-CoV-2. Accordingly, the benefits of spironolactone on clinical outcomes of COVID-19 cases have been reported $(46,47)$.

However, the replication of SARS-CoV-2 during the acute infection may overwhelm the ACE2 receptor, in which results in attachment of virus to other possible receptors, such as DPP4 (CD26), CD147, neurophilin 1, lectins, CD209L, and Tyrosine-protein kinase receptor UFO (AXL) (14,48-52). The use of DPP4 inhibitor was associated with lower mortality in diabetic COVID-19 patients $(25,27,53)$, and even could improve the clinical end points and inflammation in non-diabetic COVID-19 cases (28). The proposed mechanisms could be the immunomodulatory functions (29), reduction of virus entry and diminishing viral replication.

Sitagliptin, a DPP4 inhibitor, and spironolactone are relatively safe medications without significant adverse side effects (54-56) or crossed side effects. Therefore, the combination of sitagliptin and spironolactone would be a relatively safe approach. It can potentially improve the clinical outcomes of COVID-19 cases without increasing risk of adverse side effects. In the current study, three patients $(2.9 \%)$ reported medication related adverse side effects, such as hypotension and hypoglycemia, which were tolerable. The complications of spironolactone, (increased diuresis and orthostatic hypotension (56)) and sitagliptin (hypoglycemia (55)) can be managed by lowering the dose. 
There are a couple of limitations in the current study, including not having a double-blind design, and statistically significant difference in clinical score between two groups at initial presentation. However, given the range of 0-29, the difference of 2 points in the severity score may not be as critical because both groups average above 4 and hence are deemed comparable in terms of adverse outcome potential (35). Furthermore, almost half of the patients (57.3\% control, and $49.5 \%$ combination) had COVID-19 positive PCR results, and others had history of exposure to COVID-19 with typical manifestations. We assumed that recall bias and loss to follow-up are distributed evenly across the two cohort groups.

In conclusion, combination of sitagliptin and spironolactone can reduce hospitalization, ER visits and duration of disease in acutely ill outpatient COVID-19 cases significantly. However, running a double blind, randomized, placebo-controlled trial is required to further substantiate the beneficial effects of this combination therapy in COVID-19 patients.

\section{Acknowledgments}

The authors express their gratitude to the Shiraz University Clinics for helping with data collection.

\section{Additional Information}

Correspondence: Kamyar Asadipooya, MD, Department of Medicine, Division of Endocrinology, Diabetes, and Metabolism, Barnstable Brown Diabetes and Obesity Center, University of Kentucky, Lexington, KY 40504, USA. Email: kas224@uky.edu

Disclosure Summary: The authors have no conflicts of interest to report.

Data Availability: Shiraz University (MAD, YM, HF, FSRR, AP and MH) generated the data. University of Kentucky (KA and RA) has de-identified data and analyzed (RA) the data. The de-identified data are available for further investigations.

Authors' contributions: KA proposed the idea and designed the study. KA, RA, YM and RK wrote the manuscript. MAD, YM, HF, FSRR, AP, and MH collected the data. RA provided statistical analysis and wrote statistical part. All authors approved the final version of the manuscript. 


\section{References}

1. Hopkins J. Coronavirus resource center. Im Internet (Stand: 1904 2020): https://coronavirus jhu edu/data 2020;

2. Gao YD, Ding M, Dong X, Zhang JJ, Kursat Azkur A, Azkur D, Gan H, Sun YL, Fu W, Li W, Liang HL, Cao YY, Yan Q, Cao C, Gao HY, Brüggen MC, van de Veen W, Sokolowska M, Akdis M, Akdis CA. Risk factors for severe and critically ill COVID-19 patients: A review. Allergy 2021; 76:428-455

3. Christie A, Henley SJ, Mattocks L, Fernando R, Lansky A, Ahmad FB, Adjemian J, Anderson RN, Binder AM, Carey K, Dee DL, Dias T, Duck WM, Gaughan DM, Lyons BC, McNaghten AD, Park MM, Reses H, Rodgers L, Van Santen K, Walker D, Beach MJ. Decreases in COVID-19 Cases, Emergency Department Visits, Hospital Admissions, and Deaths Among Older Adults Following the Introduction of COVID-19 Vaccine - United States, September 6, 2020-May 1, 2021. MMWR Morbidity and mortality weekly report 2021; 70:858-864

4. Kustin T, Harel N, Finkel U, Perchik S, Harari S, Tahor M, Caspi I, Levy R, Leshchinsky M, Ken Dror S, Bergerzon G, Gadban H, Gadban F, Eliassian E, Shimron O, Saleh L, Ben-Zvi H, Keren Taraday E, Amichay D, Ben-Dor A, Sagas D, Strauss M, Shemer Avni Y, Huppert A, Kepten E, Balicer RD, Netzer D, Ben-Shachar S, Stern A. Evidence for increased breakthrough rates of SARS-CoV-2 variants of concern in BNT162b2-mRNA-vaccinated individuals. Nature medicine 2021;

5. Xie J, Wang Z, Liang J, Lin H, Yang Z, Wang Y, Liang H, Wu H, Chen R, Ou Y, Wang F, Wang Y, Wang Y, Luo W, Zhang J, Li N, Li Z, Jiang M, Li $\mathrm{S}$, Li J. Critical Review of the Scientific Evidence and Recommendations in COVID-19 Management Guidelines. Open forum infectious diseases 2021; 8:ofab376

6. Gupta A, Gonzalez-Rojas Y, Juarez E, Crespo Casal M, Moya J, Falci DR, Sarkis E, Solis J, Zheng H, Scott N, Cathcart AL, Hebner CM, Sager J, Mogalian E, Tipple C, Peppercorn A, Alexander E, Pang PS, Free A, Brinson C, Aldinger M, Shapiro AE. Early Treatment for Covid-19 with SARS-CoV-2 Neutralizing Antibody Sotrovimab. The New England journal of medicine 2021; 385:1941-1950

7. Weinreich DM, Sivapalasingam S, Norton T, Ali S, Gao H, Bhore R, Xiao J, Hooper AT, Hamilton JD, Musser BJ, Rofail D, Hussein M, Im J, Atmodjo DY, Perry C, Pan C, Mahmood A, Hosain R, Davis JD, Turner KC, Baum A, Kyratsous CA, Kim Y, Cook A, Kampman W, RoqueGuerrero L, Acloque G, Aazami H, Cannon K, Simón-Campos JA, Bocchini JA, Kowal B, DiCioccio AT, Soo Y, Geba GP, Stahl N, Lipsich L, Braunstein N, Herman G, Yancopoulos GD. REGEN-COV Antibody Combination and Outcomes in Outpatients with Covid-19. The New England journal of medicine 2021;

8. Harvey WT, Carabelli AM, Jackson B, Gupta RK, Thomson EC, Harrison EM, Ludden C, Reeve R, Rambaut A, Peacock SJ, Robertson DL. SARS-CoV-2 variants, spike mutations and immune escape. Nature reviews Microbiology 2021; 19:409-424

9. Weisblum Y, Schmidt F, Zhang F, DaSilva J, Poston D, Lorenzi JC, Muecksch F, Rutkowska M, Hoffmann HH, Michailidis E, Gaebler C, Agudelo M, Cho A, Wang Z, Gazumyan A, Cipolla M, Luchsinger L, Hillyer CD, Caskey M, Robbiani DF, Rice CM, Nussenzweig MC, Hatziioannou T, Bieniasz PD. Escape from neutralizing antibodies by SARS-CoV-2 spike protein variants. eLife 2020; 9

10. Chen RE, Zhang X, Case JB, Winkler ES, Liu Y, VanBlargan LA, Liu J, Errico JM, Xie X, Suryadevara N, Gilchuk P, Zost SJ, Tahan S, Droit L, Turner JS, Kim W, Schmitz AJ, Thapa M, Wang D, Boon ACM, Presti RM, O'Halloran JA, Kim AHJ, Deepak P, Pinto D, Fremont DH, Crowe 
JE, Jr., Corti D, Virgin HW, Ellebedy AH, Shi PY, Diamond MS. Resistance of SARS-CoV-2 variants to neutralization by monoclonal and serum-derived polyclonal antibodies. Nature medicine 2021; 27:717-726

11. Wang P, Nair MS, Liu L, Iketani S, Luo Y, Guo Y, Wang M, Yu J, Zhang B, Kwong PD, Graham BS, Mascola JR, Chang JY, Yin MT, Sobieszczyk M, Kyratsous CA, Shapiro L, Sheng Z, Huang Y, Ho DD. Antibody resistance of SARS-CoV-2 variants B.1.351 and B.1.1.7. Nature 2021; 593:130-135

12. Walls AC, Park YJ, Tortorici MA, Wall A, McGuire AT, Veesler D. Structure, Function, and Antigenicity of the SARS-CoV-2 Spike Glycoprotein. Cell 2020;

13. Vankadari N, Wilce JA. Emerging WuHan (COVID-19) coronavirus: glycan shield and structure prediction of spike glycoprotein and its interaction with human CD26. Emerg Microbes Infect 2020; 9:601-604

14. Li Y, Zhang Z, Yang L, Lian X, Xie Y, Li S, Xin S, Cao P, Lu J. The MERS-CoV Receptor DPP4 as a Candidate Binding Target of the SARS-CoV-2 Spike. iScience 2020; 23:101160

15. Wrapp D, Wang N, Corbett KS, Goldsmith JA, Hsieh CL, Abiona O, Graham BS, McLellan JS. Cryo-EM structure of the 2019-nCoV spike in the prefusion conformation. Science (New York, NY) 2020; 367:1260-1263

16. Hoffmann M, Kleine-Weber H, Schroeder S, Krüger N, Herrler T, Erichsen S, Schiergens TS, Herrler G, Wu NH, Nitsche A, Müller MA, Drosten C, Pöhlmann S. SARS-CoV-2 Cell Entry Depends on ACE2 and TMPRSS2 and Is Blocked by a Clinically Proven Protease Inhibitor. Cell 2020; 181:271-280.e278

17. Haga S, Yamamoto N, Nakai-Murakami C, Osawa Y, Tokunaga K, Sata T, Yamamoto N, Sasazuki T, Ishizaka Y. Modulation of TNF-alphaconverting enzyme by the spike protein of SARS-CoV and ACE2 induces TNF-alpha production and facilitates viral entry. Proceedings of the National Academy of Sciences of the United States of America 2008; 105:7809-7814

18. $\mathrm{Xu} \mathrm{J,} \mathrm{Xu} \mathrm{X,} \mathrm{Jiang} \mathrm{L,} \mathrm{Dua} \mathrm{K,} \mathrm{Hansbro} \mathrm{PM,} \mathrm{Liu} \mathrm{G.} \mathrm{SARS-CoV-2} \mathrm{induces} \mathrm{transcriptional} \mathrm{signatures} \mathrm{in} \mathrm{human} \mathrm{lung} \mathrm{epithelial} \mathrm{cells} \mathrm{that} \mathrm{promote}$ lung fibrosis. Respir Res 2020; 21:182

19. Li L, Liu X, Zhou Y, Wang J. On resistance to virus entry into host cells. Biophys J 2012; 102:2230-2233

20. Tomlins SA, Rhodes DR, Perner S, Dhanasekaran SM, Mehra R, Sun XW, Varambally S, Cao X, Tchinda J, Kuefer R, Lee C, Montie JE, Shah RB, Pienta KJ, Rubin MA, Chinnaiyan AM. Recurrent fusion of TMPRSS2 and ETS transcription factor genes in prostate cancer. Science (New York, NY) 2005; 310:644-648

21. Wilcox CS, Pitt B. Is Spironolactone the Preferred Renin-Angiotensin-Aldosterone Inhibitor for Protection Against COVID-19? J CardiovasC Pharmacol 2020; 77:323-331

22. Satoh M, Ishikawa Y, Minami Y, Akatsu T, Nakamura M. Eplerenone inhibits tumour necrosis factor alpha shedding process by tumour necrosis factor alpha converting enzyme in monocytes from patients with congestive heart failure. Heart 2006; 92:979-980

23. Dong D, Fan TT, Ji YS, Yu JY, Wu S, Zhang L. Spironolactone alleviates diabetic nephropathy through promoting autophagy in podocytes. Int Urol Nephrol 2019; 51:755-764

24. Keidar S, Gamliel-Lazarovich A, Kaplan M, Pavlotzky E, Hamoud S, Hayek T, Karry R, Abassi Z. Mineralocorticoid receptor blocker increases angiotensin-converting enzyme 2 activity in congestive heart failure patients. Circ Res 2005; 97:946-953 
25. Solerte SB, D'Addio F, Trevisan R, Lovati E, Rossi A, Pastore I, Dell'Acqua M, Ippolito E, Scaranna C, Bellante R, Galliani S, Dodesini AR, Lepore G, Geni F, Fiorina RM, Catena E, Corsico A, Colombo R, Mirani M, De Riva C, Oleandri SE, Abdi R, Bonventre JV, Rusconi S, Folli F, Di Sabatino A, Zuccotti G, Galli M, Fiorina P. Sitagliptin Treatment at the Time of Hospitalization Was Associated With Reduced Mortality in Patients With Type 2 Diabetes and COVID-19: A Multicenter, Case-Control, Retrospective, Observational Study. Diabetes care 2020;

26. Montastruc F, Romano C, Montastruc JL, Silva S, Seguin T, Minville V, Georges B, Riu-Poulenc B, Fourcade O. Pharmacological characteristics of patients infected with SARS-Cov-2 admitted to Intensive Care Unit in South of France. Therapie 2020;

27. Rakhmat, II, Kusmala YY, Handayani DR, Juliastuti H, Nawangsih EN, Wibowo A, Lim MA, Pranata R. Dipeptidyl peptidase-4 (DPP-4) inhibitor and mortality in coronavirus disease 2019 (COVID-19) - A systematic review, meta-analysis, and meta-regression. Diabetes \& metabolic syndrome 2021; $15: 777-782$

28. Al-Kuraishy HM, Al-Gareeb Al, Qusty N, Alexiou A, Batiha GE. Impact of Sitagliptin in Non-Diabetic Covid-19 Patients. Current molecular pharmacology 2021;

29. Shao S, Xu Q, Yu X, Pan R, Chen Y. Dipeptidyl peptidase 4 inhibitors and their potential immune modulatory functions. Pharmacology \& therapeutics 2020:107503

30. Qi F, Qian S, Zhang S, Zhang Z. Single cell RNA sequencing of 13 human tissues identify cell types and receptors of human coronaviruses Biochemical and biophysical research communications 2020; 526:135-140

31. Rahimi F, Talebi Bezmin Abadi A. Emergence of the Delta Plus variant of SARS-CoV-2 in Iran. Gene reports 2021; $25: 101341$

32. Garcia M, Lipskiy N, Tyson J, Watkins R, Esser ES, Kinley T. Centers for Disease Control and Prevention 2019 novel coronavirus disease (COVID-19) information management: addressing national health-care and public health needs for standardized data definitions and codified vocabulary for data exchange. Journal of the American Medical Informatics Association : JAMIA 2020; 27:1476-1487

33. Blair JE, Gotimukul A, Wang F, Mina SA, Bartels HC, Burns MW, Kole AE, Vikram HR, Gea-Banacloche JC, Seville MT, Petty SAB, Vikram A, Orenstein R. Mild to moderate COVID-19 illness in adult outpatients: Characteristics, symptoms, and outcomes in the first 4 weeks of illness. Medicine 2021; 100:e26371

34. Rahmanzade R, Rahmanzadeh R, Hashemian SM, Tabarsi P. Iran's Approach to COVID-19: Evolving Treatment Protocols and Ongoing Clinical Trials. Frontiers in public health 2020; 8:551889

35. Goodacre S, Thomas B, Sutton L, Burnsall M, Lee E, Bradburn M, Loban A, Waterhouse S, Simmonds R, Biggs K, Marincowitz C, Schutter J, Connelly S, Sheldon E, Hall J, Young E, Bentley A, Challen K, Fitzsimmons C, Harris T, Lecky F, Lee A, Maconochie I, Walter D. Derivation and validation of a clinical severity score for acutely ill adults with suspected COVID-19: The PRIEST observational cohort study. PloS one 2021; $16: \mathrm{e} 0245840$

36. Tsang HF, Chan LWC, Cho WCS, Yu ACS, Yim AKY, Chan AKC, Ng LPW, Wong YKE, Pei XM, Li MJW, Wong SC. An update on COVID-19 pandemic: the epidemiology, pathogenesis, prevention and treatment strategies. Expert review of anti-infective therapy 2021; 19:877888

37. Peacocke EF, Heupink LF, Frønsdal K, Dahl EH, Chola L. Global access to COVID-19 vaccines: a scoping review of factors that may influence equitable access for low and middle-income countries. BMJ open 2021; 11:e049505 
38. McCullough PA, Kelly RJ, Ruocco G, Lerma E, Tumlin J, Wheelan KR, Katz N, Lepor NE, Vijay K, Carter H, Singh B, McCullough SP, Bhambi BK, Palazzuoli A, De Ferrari GM, Milligan GP, Safder T, Tecson KM, Wang DD, McKinnon JE, O'Neill WW, Zervos M, Risch HA.

Pathophysiological Basis and Rationale for Early Outpatient Treatment of SARS-CoV-2 (COVID-19) Infection. The American journal of medicine 2021; 134:16-22

39. Edwards C. New Horizons: Does Mineralocorticoid Receptor Activation by Cortisol Cause ATP Release and COVID-19 Complications? The Journal of clinical endocrinology and metabolism 2021; 106:622-635

40. Bardaweel SK, Hajjo R, Sabbah DA. Sitagliptin: a potential drug for the treatment of COVID-19? Acta pharmaceutica (Zagreb, Croatia) 2021; 71:175-184

41. Monteil V, Kwon H, Prado P, Hagelkrüys A, Wimmer RA, Stahl M, Leopoldi A, Garreta E, Hurtado Del Pozo C, Prosper F, Romero JP, Wirnsberger G, Zhang H, Slutsky AS, Conder R, Montserrat N, Mirazimi A, Penninger JM. Inhibition of SARS-CoV-2 Infections in Engineered Human Tissues Using Clinical-Grade Soluble Human ACE2. Cell 2020; 181:905-913.e907

42. Wysocki J, Ye M, Hassler L, Gupta AK, Wang Y, Nicoleascu V, Randall G, Wertheim JA, Batlle D. A Novel Soluble ACE2 Variant with Prolonged Duration of Action Neutralizes SARS-CoV-2 Infection in Human Kidney Organoids. Journal of the American Society of Nephrology : JASN 2021; 32:795-803

43. Heurich A, Hofmann-Winkler H, Gierer S, Liepold T, Jahn O, Pöhlmann S. TMPRSS2 and ADAM17 cleave ACE2 differentially and only proteolysis by TMPRSS2 augments entry driven by the severe acute respiratory syndrome coronavirus spike protein. Journal of virology 2014; 88:1293-1307

44. Kuba K, Imai Y, Rao S, Gao H, Guo F, Guan B, Huan Y, Yang P, Zhang Y, Deng W, Bao L, Zhang B, Liu G, Wang Z, Chappell M, Liu Y, Zheng D, Leibbrandt A, Wada T, Slutsky AS, Liu D, Qin C, Jiang C, Penninger JM. A crucial role of angiotensin converting enzyme 2 (ACE2) in SARS coronavirus-induced lung injury. Nat Med 2005; 11:875-879

45. Verdecchia P, Cavallini C, Spanevello A, Angeli F. The pivotal link between ACE2 deficiency and SARS-CoV-2 infection. Eur J Intern Med 2020; 76:14-20

46. Jeon D, Son M, Choi J. Effect of Spironolactone on COVID-19 in Patients With Underlying Liver Cirrhosis: A Nationwide Case-Control Study in South Korea. Frontiers in medicine 2021; 8:629176

47. Mareev VY, Orlova YA, Plisyk AG, Pavlikova EP, Matskeplishvili ST, Akopyan ZA, Seredenina EM, Potapenko AV, Agapov MA, Asratyan DA, Dyachuk LI, Samokhodskaya LM, Mershina E, Sinitsyn VE, Pakhomov PV, Bulanova MM, Fuks AA, Mareev YV, Begrambekova YL, Kamalov A. Results of Open-Label non-Randomized Comparative Clinical Trial: "BromhexIne and Spironolactone for CoronavirUs Infection requiring hospiTalization (BISCUIT). Kardiologiia 2020; 60:4-15

48. Cantuti-Castelvetri L, Ojha R, Pedro LD, Djannatian M, Franz J, Kuivanen S, van der Meer F, Kallio K, Kaya T, Anastasina M, Smura T, Levanov L, Szirovicza L, Tobi A, Kallio-Kokko H, Österlund P, Joensuu M, Meunier FA, Butcher SJ, Winkler MS, Mollenhauer B, Helenius A, Gokce O, Teesalu T, Hepojoki J, Vapalahti O, Stadelmann C, Balistreri G, Simons M. Neuropilin-1 facilitates SARS-CoV-2 cell entry and infectivity. Science (New York, NY) 2020; 370:856-860 
49. Wang S, Qiu Z, Hou Y, Deng X, Xu W, Zheng T, Wu P, Xie S, Bian W, Zhang C, Sun Z, Liu K, Shan C, Lin A, Jiang S, Xie Y, Zhou Q, Lu L, Huang $\mathrm{J}, \mathrm{Li} X . \mathrm{AXL}$ is a candidate receptor for SARS-CoV-2 that promotes infection of pulmonary and bronchial epithelial cells. Cell research 2021; 31:126-140

50. Jeffers SA, Tusell SM, Gillim-Ross L, Hemmila EM, Achenbach JE, Babcock GJ, Thomas WD, Jr., Thackray LB, Young MD, Mason RJ, Ambrosino DM, Wentworth DE, Demartini JC, Holmes KV. CD209L (L-SIGN) is a receptor for severe acute respiratory syndrome coronavirus. Proceedings of the National Academy of Sciences of the United States of America 2004; 101:15748-15753

51. Jackson CB, Farzan M, Chen B, Choe H. Mechanisms of SARS-CoV-2 entry into cells. Nature reviews Molecular cell biology 2022; 23:3-20

52. Zhang Q, Xiang R, Huo S, Zhou Y, Jiang S, Wang Q, Yu F. Molecular mechanism of interaction between SARS-CoV-2 and host cells and interventional therapy. Signal transduction and targeted therapy 2021; 6:233

53. Patoulias D, Doumas M. Dipeptidyl Peptidase-4 Inhibitors and COVID-19-Related Deaths among Patients with Type 2 Diabetes Mellitus: A Meta-Analysis of Observational Studies. Endocrinology and metabolism (Seoul, Korea) 2021; 36:904-908

54. Deacon CF. Dipeptidyl peptidase 4 inhibitors in the treatment of type 2 diabetes mellitus. Nature reviews Endocrinology 2020; 16:642653

55. Stoian AP, Sachinidis A, Stoica RA, Nikolic D, Patti AM, Rizvi AA. The efficacy and safety of dipeptidyl peptidase-4 inhibitors compared to other oral glucose-lowering medications in the treatment of type 2 diabetes. Metabolism: clinical and experimental 2020; 109:154295

56. Martin KA, Anderson RR, Chang RJ, Ehrmann DA, Lobo RA, Murad MH, Pugeat MM, Rosenfield RL. Evaluation and Treatment of Hirsutism in Premenopausal Women: An Endocrine Society Clinical Practice Guideline. The Journal of clinical endocrinology and metabolism 2018; 103:1233-1257 
Table 1. OPD clinical severity score determines the severity of the disease based on clinical conditions, functional performance and oxygen requirement. The raising scores means worse clinical status (35).

\begin{tabular}{r|l} 
Variable & Range \\
\hline Respiratory rate per minute & $0-3$ \\
Oxygen saturation \% & $0-3$ \\
Heart rate per minute & $0-3$ \\
Systolic blood pressure mmHg & $0-3$ \\
Temperature & $0-3$ \\
Alertness & 0 and 3 \\
Inspired oxygen & 0 and 2 \\
Sex & 0 and 1 \\
Age (years) & $0-4$ \\
Total score & 29
\end{tabular}




\begin{tabular}{|l|l|l|}
\hline Variable & Range & Score \\
\hline Sex & Female & 0 \\
\hline Respiratory rate per minute & Male & 1 \\
\cline { 2 - 3 } & $12-20$ & 0 \\
\cline { 2 - 3 } & $9-11$ & 1 \\
\cline { 2 - 3 } & $21-24$ & 2 \\
\cline { 2 - 3 } & $<9$ or $>24$ & 3 \\
\hline Oxygen saturation $(\%)$ & $>95$ & 0 \\
\cline { 2 - 3 } & $94-95$ & 1 \\
\cline { 2 - 3 } & $92-93$ & 2 \\
\cline { 2 - 3 } & $<92$ & 3 \\
\hline Heart rate per minute & $51-90$ & 0 \\
\cline { 2 - 3 } & $41-50$ or $91-110$ & 1 \\
\cline { 2 - 3 } & $111-130$ & 2 \\
\cline { 2 - 3 } & $<41$ or $>130$ & 3 \\
\hline Systolic blood pressure mmHg & $111-219$ & 0 \\
\cline { 2 - 3 } & $101-110$ & 1 \\
\cline { 2 - 3 } & $91-100$ & 2 \\
\cline { 2 - 3 } & $<91$ or $>219$ & 3 \\
\hline
\end{tabular}

\begin{tabular}{|c|c|c|}
\hline Variable & Range & Score \\
\hline \multirow[t]{4}{*}{ Temperature ${ }^{\circ} \mathrm{C}$} & $36.1-38.0$ & 0 \\
\hline & $35.1-36.0$ or $38.1-39.0$ & 1 \\
\hline & $>39.0$ & 2 \\
\hline & $<35.1$ & 3 \\
\hline \multirow[t]{2}{*}{ Alertness } & Alert & 0 \\
\hline & Confused or disoriented & 3 \\
\hline \multirow{2}{*}{$\begin{array}{l}\text { Oxygen } \\
\text { requirement }\end{array}$} & No nasal oxygen & 0 \\
\hline & Nasal oxygen & 2 \\
\hline \multirow[t]{4}{*}{ Age per years } & $18-49$ & 0 \\
\hline & $50-65$ & 2 \\
\hline & $66-80$ & 3 \\
\hline & $>80$ & 4 \\
\hline \multirow{5}{*}{$\begin{array}{l}\text { Functional } \\
\text { performance }\end{array}$} & Normal activity, no restriction & 0 \\
\hline & Mild to moderate limitation & 1 \\
\hline & Limited activity and self-care & 2 \\
\hline & Limited to self-care & 3 \\
\hline & Bed ridden & 4 \\
\hline Total score & & 29 \\
\hline
\end{tabular}


Table 2. The baseline characteristics and outcomes of the study population

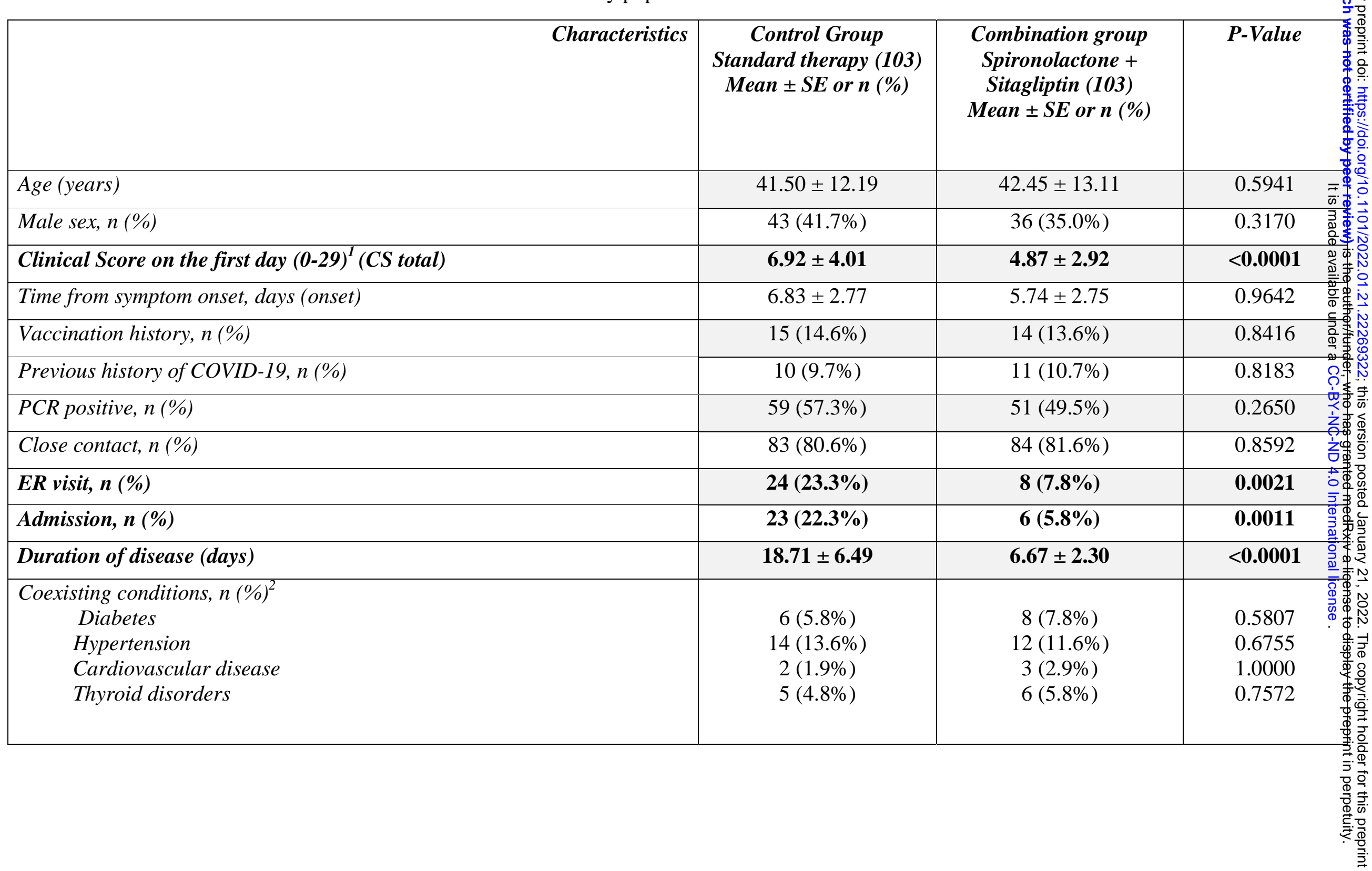




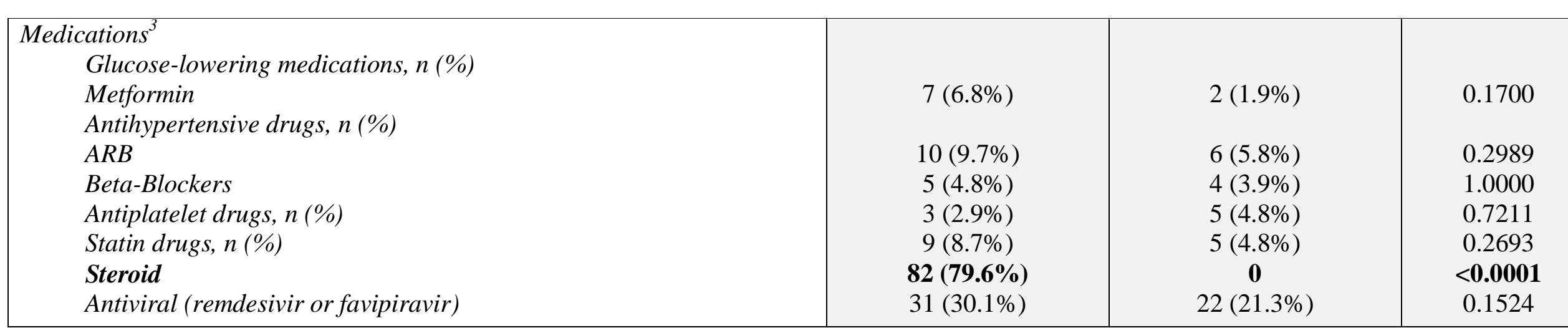

Data are mean \pm SEM unless otherwise indicated. $n$, number.

${ }^{1}$ Modified clinical scores determine severity of clinical condition and probability of hospitalization (table 1). The score greater than four has high sensitivity for predicting adverse outcomes.

${ }^{2}$ The coexisting disorders include diabetes (on medication or hemoglobin A1C > 6.5), hypertension (on medication or blood pressure $>$ 140/90), cardiovascular disease, renal disease, liver disease, lung disease, neurologic disorder, cancer, hematologic disorder, immune deficiency (transplant etc.), rheumatology disorder and hypothyroidism. There were no differences about kidney disease, lung disease, liver disease, cancer, hematologic disorder, immune deficiency (transplant etc.), neurologic disorder, and rheumatology disorder.

${ }^{3}$ There were no differences concerning ACE inhibitor, anticoagulants, insulin and other oral hypoglycemic agent users. 
Table 3. Odds ratio for hospitalization for outpatient COVID-19 cases

\begin{tabular}{l|cc}
\multicolumn{1}{l}{ Variable } & Odds ratio (95\% confidence & P-Value \\
interval) & \\
\hline Age & $1.026(0.986-1.068)$ & 0.1987 \\
Sex (female vs male) & $0.437(0.185-1.031)$ & 0.0588 \\
Combination vs Control & $0.177(0.065-0.486)$ & 0.0008 \\
Vaccination history, yes vs no & $1.015(0.302-3.410)$ & 0.9809 \\
Previous history of COVID-19, yes vs no & $0.637(0.126-3.223)$ & 0.5859 \\
Comorbidities, yes vs no & $3.104(1.110-8.678)$ & 0.0308
\end{tabular}

${ }^{1}$ Comorbidities consist of diabetes, hypertension, cardiovascular disease, chronic kidney disease, chronic lung disease, chronic liver disease, hypothyroidism, rheumatologic disease, neurologic disease, immune deficiency (transplant etc.), hematologic disorder and cancer. 
Figure 1. The Kaplan-Meier survival curves indicates the difference between the hospitalizations across the groups. The hospitalization curve for combination group was lower than control group.

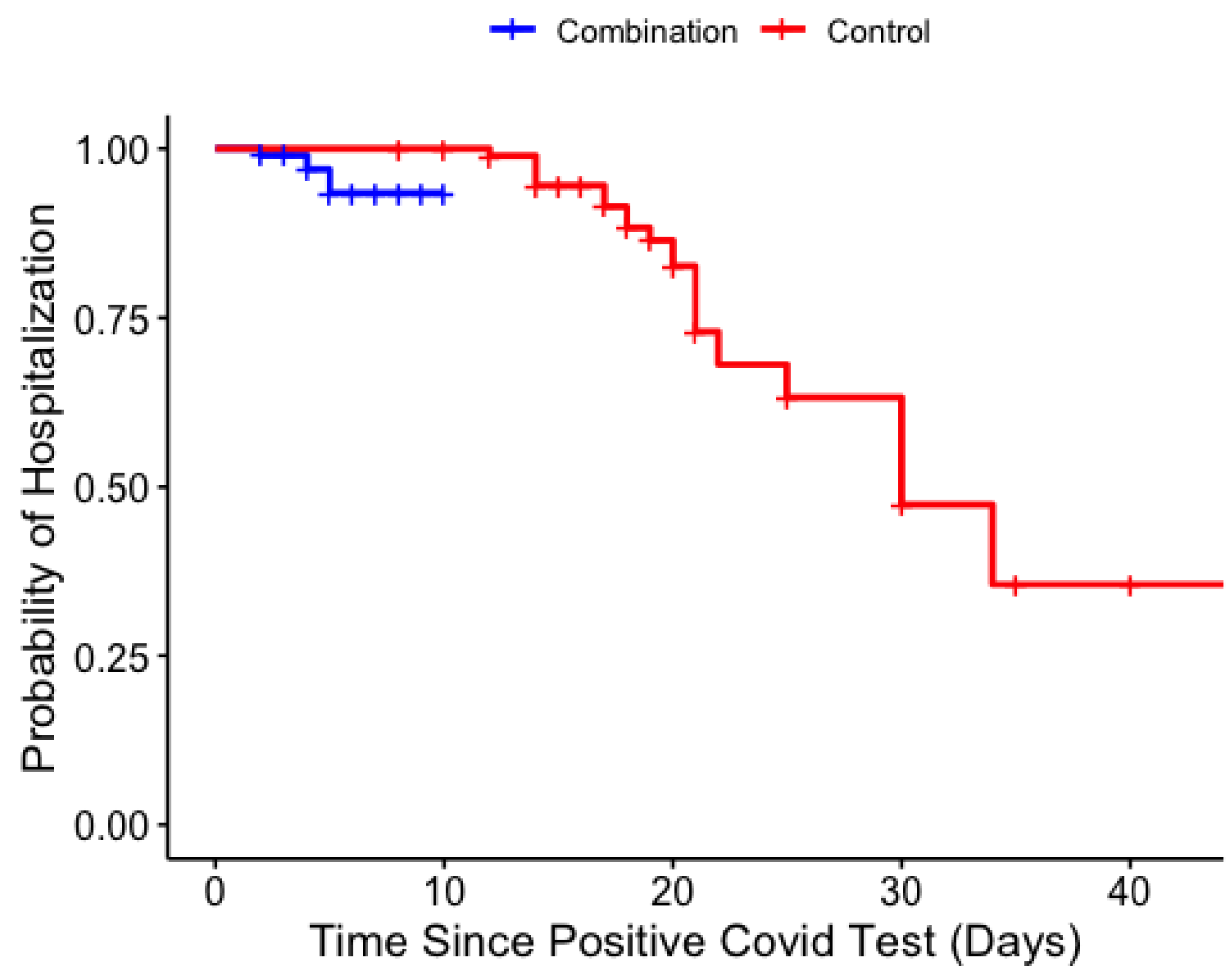

